\title{
Biometric Analysis of Cataract Surgery on Adult Candidates in Shanghai, China
}

\author{
C-L Feng, Y-Z Yuan, F Yuan, X-P Ma, C-H Zhang
}

\begin{abstract}
Objective: To describe the variation in ocular biometry and investigate the relationship among the parameters of the cataract surgery of adult candidates in Zhongshan Hospital, Fudan University, Shanghai, China.

Methods: This was a cross-sectional study that included 1975 cataract patients (1975 eyes) aged from 18 to 95 years old. Axial length (AL), corneal curvature, anterior chamber depth (ACD) and horizontal corneal diameter (white-to-white [WTW] distance) were optically measured by partial coherence interferometry (IOL Master). Spearman rank correlation coefficients were used to evaluate bivariate correlations.

Results: The average AL and the mean corneal curvature were $24.86 \pm 2.72 \mathrm{~mm}$ and $44.13 \pm$ $1.58 D$, respectively. The mean $A C D$ and $W T W$ were $3.11 \pm 0.50 \mathrm{~mm}$ and $11.83 \pm 0.42 \mathrm{~mm}$, respectively. The mean corneal curvature was negatively correlated with AL, especially in the range of $A L$ from $22 \mathrm{~mm}$ to $25 \mathrm{~mm}$, while $A C D$ and WTW were positively correlated with $A L$. However, the correlation coefficient between $A L$ and $W T W$ was relatively low.

Conclusions: Slight corneal astigmatism, especially against-the-rule (ATR) astigmatism, was common in cataract patients. Corneal curvature seemed to be relatively flat to compensate for the long axial length achieving the emmetropic state in limited range. Corneal expansion was limited with the increasing of axial length.
\end{abstract}

Keywords: Anterior chamber depth, axial length, cataract, corneal astigmatism, corneal curvature, horizontal corneal diameter

\section{BioAnálisis Biométrico de Candidatos a Cirugía de Cataratas de Adultos en Shanghai, China \\ C-L Feng, Y-Z Yuan, F Yuan, X-P Ma, C-H Zhang}

\begin{abstract}
RESUMEN
Objetivo: Describir la variación en la biometría ocular e investigar la relación entre los parámetros de los candidatos de cirugía de cataratas de adultos en el Hospital Zhongshan de la Universidad de Fudan, Shanghai, China.

Métodos: Se trató de un estudio transversal que incluyó 1975 pacientes de catarata (1975 ojos) en edades de 18 a 95 años. La longitud axial (LA), la curvatura corneal, profundidad de la cámara anterior (PCA), y el diámetro corneal horizontal (distancia blanco-blanco[B-B]), fueron medidos ópticamente mediante interferometría de coherencia parcial (IOL Master). Para evaluar las correlaciones bivariadas, se utilizaron coeficientes de correlación de Spearman.

Resultados: El promedio de LA y la curvatura corneal media fueron $24.86 \pm 2.72 \mathrm{~mm}$ y 44.13 $\pm 1.58 \mathrm{D}$, respectivamente. La PCA y $B$-B fueron $3.11 \pm 0.50 \mathrm{~mm}$ y $11.83 \pm 0,42 \mathrm{~mm}$, respectivamente. La curvatura corneal media se correlacionó negativamente con LA, especialmente en
\end{abstract}

From: Department of Ophthalmology, Zhongshan Hospital, Fudan University, Shanghai, China.
Correspondence: Dr F Yuan, Department of Ophthalmology, Zhongshan Hospital, Fudan University, 180 Fenglin Road, Shanghai 200032, China. Email: yuanfei121@yeah.net 
el rango de LA de $22 \mathrm{~mm}$ a $25 \mathrm{~mm}$, mientras que PCA y B-B se correla-cionaron positivamente con $L A$. Sin embargo, el coeficiente de correlación entre $L A$ y $B$ - $B$ fue relativamente bajo.

Conclusiones: El astigmatismo corneal leve, especialmente el astigmatismo inverso o contra la regla (ACR), fue común en pacientes con cataratas. Curvatura corneal parecía estar relativamente plana para compensar la longitud de un largo axial que alcance un estado emétrope en un rango limitado. La expansión córnea se limitó con el aumento de la longitud axial.

Palabras claves: Astigmatismo corneal, profundidad de cámara anterior, longitud axial, catarata, curvatura corneal, diámetro corneal horizontal

West Indian Med J 2017; 66 (2): 221

\section{INTRODUCTION}

With the development of techniques and instruments in cataract surgery, it has gradually become a refractive procedure. Besides, patients expect better vision quality after surgery. The optical parameters of the eyeball are especially important for cataract surgery candidates. They are essential in calculating the intraocular lens (IOL) power and directly affect the visual outcome after cataract surgery.

Most studies on ocular biometric parameters were focussed on children $(1,2)$ and selected groups, such as university students $(3,4)$ and Marfan syndrome (5). For cataract patients, most studies were about corneal astigmatism (6-9) and paediatric patients with cataracts (10, 11). What is the relation among optical parameters of cataract candidates? Even though there are reports in the literature on ocular biometric parameters (12-17), there are only few reports on the Chinese cataract population $(7,18,19)$. In this study, we attempted to investigate the biometric characteristics and the relation among the parameters of Chinese cataract surgery candidates.

\section{SUBJECTS AND METHODS}

The datasets of cataract surgery candidates from March 2011 to September 2013, was acquired from the Zhongshan Hospital, Fudan University, Shanghai, China. Ethical approval for this study was obtained from the Ethics Committee of the Hospital. The eligibility criteria were cataract surgery candidates 18 years old or older, non-contact lens wearer, no corneal diseases or ocular disease which affected the measurements by partial coherence interferometry (IOLMaster). These ocular included retinal detachment and vitreous haemorrhage. Besides, the candidates were those without a history of ocular trauma or ophthalmologic operation.
Axial length (AL), corneal curvature, anterior chamber depth (ACD), and horizontal corneal diameter (white-to-white (WTW) distance) were optically measured by partial coherence interferometry (IOLMaster). The data for right eyes only were presented, apart from the asymmetry analyses.

In order to identify the pattern of astigmatism, negative cylinder axes of corneal astigmatism were classified as with-the-rule (WTR, $0^{\circ}$ to $30^{\circ}$ and $151^{\circ}$ to $180^{\circ}$ ), against-the-rule (ATR, $61^{\circ}$ to $120^{\circ}$ ) and oblique $\left[31^{\circ}\right.$ to $60^{\circ}$ and $121^{\circ}$ to $150^{\circ}$ ] (13).

Descriptive statistics (the mean and SD; median, range and percentiles) of optical parameters measurements were computed, together with $95 \%$ confidence interval. Bivariate correlations were evaluated using the Spearman rank correlation coefficient. All statistical analyses were two-sided with $p<0.05$ defined as statistically significant. Statistical data were analysed by SPSS software (version 16.0, SPSS, Inc).

\section{RESULTS}

This study included 1975 data sets of cataract adult patients' right eyes. Demographics and ocular biometry of these patients were shown in Table 1.

Table 2 shows the patients' corneal astigmatism distribution. As shown in Figure 1 and Table 2, most cataract patients had about $1.00 \mathrm{D}$ corneal astigmatism and against-the-rule (ATR) corneal astigmatism was more common in the cataract surgery adult candidates. Males were more susceptible to ATR astigmatism than female.

The mean corneal curvature $(\mathrm{Km})$ was negatively correlated with the axial length $(p=-0.301)$ and the correlation was highly statistically significant $(p=0.000)$. The anterior chamber depth (ACD) and horizontal corneal diameter (white-to-white (WTW) distance) were positively correlated with the axial length $\left(\rho_{\mathrm{ACD}}=0.589\right.$, $\left.\rho_{\mathrm{WTW}}=0.211\right)$. Besides, the correlations were highly 
Table 1: Patients' demographics and ocular biometry

\begin{tabular}{llllllll}
\hline Gender & $\mathbf{n}$ & Age $(\mathbf{y})$ & K1(D) & K2(D) & AL(mm) & ACD(mm) & WTW(mm) \\
\hline Male & 857 & $72.15 \pm 11.53$ & $43.20 \pm 1.54$ & $44.22 \pm 1.56$ & $25.07 \pm 2.62$ & $3.18 \pm 0.49$ & $11.95 \pm 0.42$ \\
& $43.39 \%$ & $18 \sim 95$ & $33.37 \sim 48.21$ & $35.09 \sim 49.55$ & $19.22 \sim 37.43$ & $1.90 \sim 4.75$ & $10.16 \sim 13.67$ \\
Female & 1118 & $71.17 \pm 10.46$ & $43.89 \pm 1.59$ & $44.99 \pm 1.61$ & $24.70 \pm 2.79$ & $3.06 \pm 0.50$ & $11.74 \pm 0.40$ \\
& $56.61 \%$ & $18 \sim 93$ & $35.67 \sim 49.07$ & $37.01 \sim 50.31$ & $20.03 \sim 36.63$ & $1.85 \sim 5.14$ & $10.44 \sim 13.32$ \\
Total & 1975 & $71.60 \pm 10.95$ & $43.60 \pm 1.60$ & $44.66 \pm 1.64$ & $24.86 \pm 2.72$ & $3.11 \pm 0.50$ & $11.83 \pm 0.42$ \\
& & $18 \sim 95$ & $33.37 \sim 49.07$ & $35.09 \sim 50.31$ & $19.22 \sim 37.43$ & $1.85 \sim 5.14$ & $10.16 \sim 13.67$ \\
\hline
\end{tabular}

$\mathrm{n}=$ number, $\mathrm{K} 1=$ flat keratometry, $\mathrm{K} 2$ = steep keratometry, Data are expressed as the mean $\pm \mathrm{SD}$ and with the range. AL: axial length; ACD: anterior chamber depth; WTW: white-to-white

Table 2: Patients' corneal astigmatism

\begin{tabular}{llllllll}
\hline Gender & $\mathbf{n}$ & Age (y) & Km (D) & $\begin{array}{l}\text { Corneal } \\
\text { Astigmatism (D) }\end{array}$ & WTR & ATR & Oblique \\
& & & & & & \\
\hline Male & 857 & $72.15 \pm 11.53$ & $43.71 \pm 1.51$ & $1.01 \pm 0.71$ & 250 & 432 & 175 \\
& $43.39 \%$ & $18 \sim 95$ & $34.23 \sim 48.42$ & $0.05 \sim 6.12$ & $29.17 \%$ & $50.41 \%$ & $20.42 \%$ \\
Female & 1118 & $71.17 \pm 10.46$ & $44.44 \pm 1.56$ & $1.10 \pm 0.73$ & 370 & 536 & 212 \\
& $56.61 \%$ & $18 \sim 93$ & $36.34 \sim 49.37$ & $0.07 \sim 4.66$ & $33.09 \%$ & $47.94 \%$ & $18.96 \%$ \\
Total & 1975 & $71.60 \pm 10.95$ & $44.13 \pm 1.58$ & $1.06 \pm 0.72$ & 620 & 968 & 387 \\
& & $18 \sim 95$ & $34.23 \sim 49.37$ & $0.05 \sim 6.12$ & $31.39 \%$ & $49.01 \%$ & $19.59 \%$ \\
\hline
\end{tabular}

$\mathrm{n}=$ number, $\mathrm{Km}=(\mathrm{K} 1+\mathrm{K} 2) / 2, \mathrm{~K} 1=$ flat keratometry, $\mathrm{K} 2=$ steep keratometry, Data are expressed as the mean $\pm \mathrm{SD}$ and with the range. WTR: with-the-rule; ATR: against-the-rule

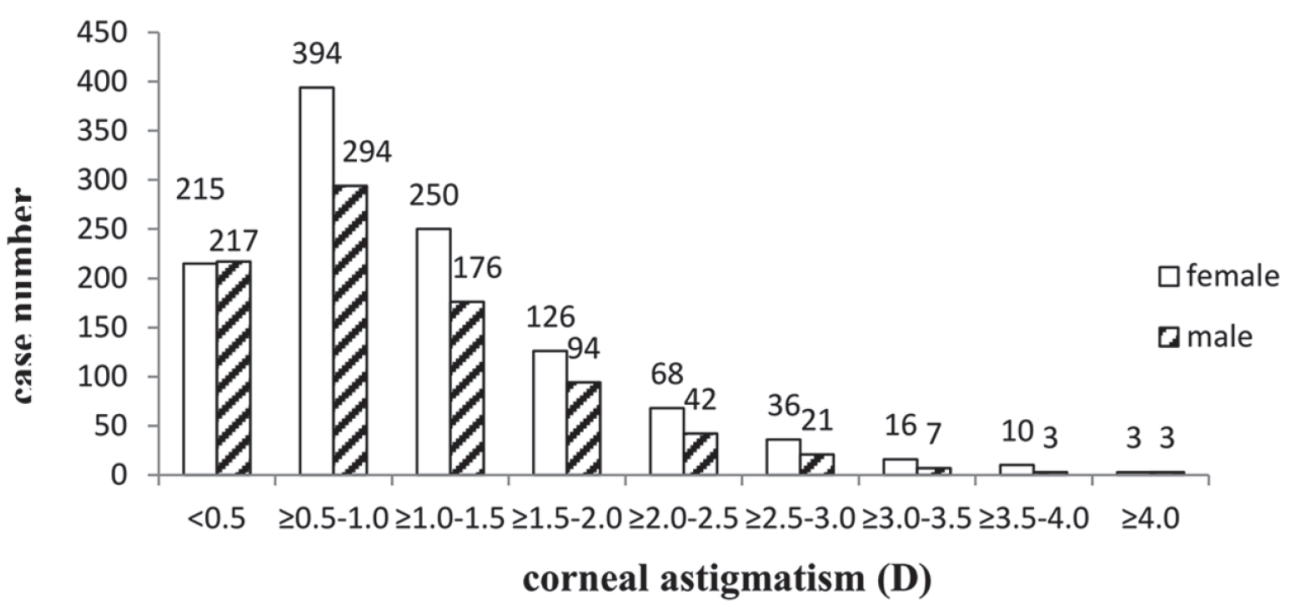

Fig. 1: The number of female and male patients with corneal astigmatism distribution in $0.5 \mathrm{D}$ steps in the entire sample (1975 eyes)

statistically significant $(p=0.000)$. The scatter diagram of the relation of AL and Km is shown in Fig. 2.

The distribution of the spots was close to the line in the range of AL from $22 \mathrm{~mm}$ to $25 \mathrm{~mm}$. However, the spots were chaotic out of that range. Furthermore, we analysed the datasets of the range from $22 \mathrm{~mm}$ to $25 \mathrm{~mm}$ and found that the negative correlation between them increased $(p=-0.438, p=0.000)$.

\section{DISCUSSION}

In this study, we retrospectively analysed adult patient cataract datasets of ocular biometry. Most cataract candidates' corneal astigmatism was $1.00 \mathrm{D}$. We found that $43.29 \%$ astigmatism $\geq 1.00 \mathrm{D}$ and ATR corneal astigmatism $(49.01 \%)$ was more common. It was more common for men to have ATR astigmatism than women. This result is similar to other studies reported in 


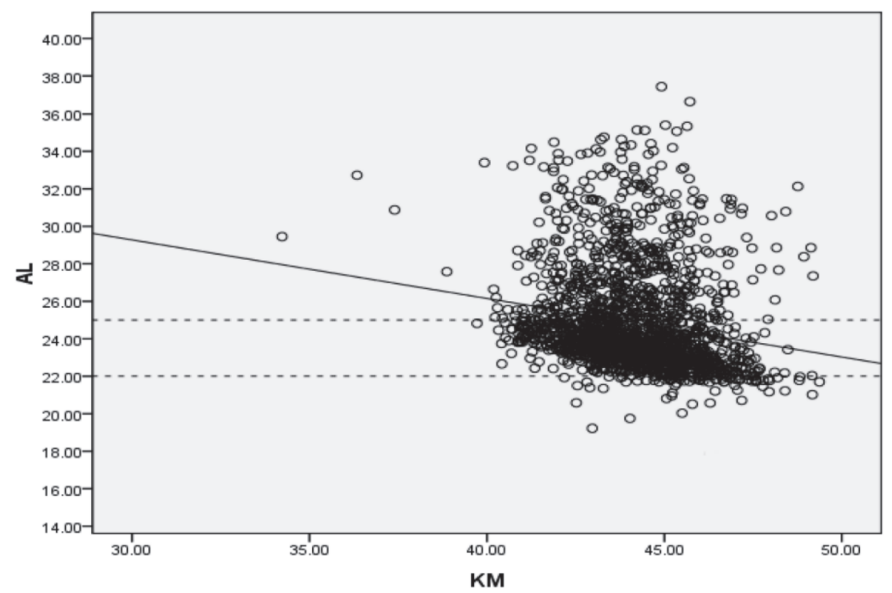

Fig. 2: Showed the scatter diagram of the relationship of the AL and the KM. The two dotted lines showed the interval of AL between $22 \mathrm{~mm}$ and $25 \mathrm{~mm}$. The full line was matching the distribution of scatter plots in the interval of AL between $22 \mathrm{~mm}$ and $25 \mathrm{~mm}$.

the literature $(6,8,9,18)$. Refractive power of the cornea occupied approximately $2 / 3$ power of the eye, and the corneal astigmatism occupied $90 \%$ of the total astigmatism. Astigmatism affected the clarity of the retinal imaging and $1.00 \mathrm{D}$ of astigmatism could introduce about $0.3 \%$ in image distortion (20). Cataract surgeons should pay more attention to corneal astigmatism, especially ATR corneal astigmatism.

In this study, the mean corneal curvature $(\mathrm{Km})$ was negatively correlated with the axial length, especially in the range of AL from $22 \mathrm{~mm}$ to $25 \mathrm{~mm}$. Corneal curvature deviated more from normal in both longer and shorter eyes. Axial length, corneal curvature and refraction of the lens were three important factors of the ocular refraction state. Tendency of myopia was caused by longer eyes, steeper corneal curvature and greater power of lens. In our study, flatter mean corneal curvature was more possible with the longer axial length in normal population with normal axial length (22 $\mathrm{mm}$ to $25 \mathrm{~mm}$ ). One possible explanation of this phenomenon was that the eye had the tendency of adjusting its structure to achieve the emmetropic state, which may be one of the mechanisms of emmetropization. Elabjer, found that keratometry of the horizontal (K1) and vertical meridian (K2) showed negative correlations with the vitreal body $(\mathrm{CV}$ ) and $\mathrm{AL}$ on both eyes (for $\mathrm{K} 1 \mathrm{r}=-0.64$ for $\mathrm{CV} \mathrm{r}=-$ 0.54 for $\mathrm{AL}$; for $\mathrm{K} 2 \mathrm{r}=-0.67$ for $\mathrm{CV} \mathrm{r}=-0.68$ for $\mathrm{AL}$ ) of emmetropes (12). Significant correlations were found between AL and flat $(r=-0.54, p=0.001)$ and steep keratometric readings $(\mathrm{r}=-0.49, p=0.001)$ in normal population (15). However, Hoffmann, found that in eyes with extreme myopia or hyperopia the correlation of $\mathrm{AL}$ with corneal radius, ACD and corneal diameter in normal eyes was not proposed (13). Comparing with results of the literatures mentioned above, our study showed that the correlation coefficient of corneal curvature with axial length was relatively low. The discrepancy might partly be due to the differences of population in these studies. Their research mainly focussed on emmetropes or normal population and the axial lengths in their studies were shorter than those in our study.

The ACD was positively correlated with the axial length $\left(\rho_{\mathrm{ACD}}=0.589, p=0.000\right)$ which was consistent with the results in other studies $(12,21)$. Besides, the correlation coefficient was a little higher compared with other studies and this might be due to the longer axial length in our study. Furthermore, another reason might be that ACD was affected by the expansion of lens with the development of cataract.

In the current study, the horizontal corneal diameter was positively correlated with the axial length however, the correlation coefficient was very-low $\left(\rho_{\mathrm{WTW}}=\right.$ $0.211, p=0.000$ ). Corneal expansion was relatively limited with the increasing of axial length.

In conclusion, we found that Chinese adult cataract candidates of this study had longer axial length than in similar reports from other regions. Slight corneal astigmatism especially ATR astigmatism was common in the cataract patients. Corneal curvature seemed to be relatively flat to compensate the long axial length and further achieving the emmetropic state in the limited range. Besides the above, ACD and WTW were positively correlated with the axial length and the coefficient of ACD was relatively higher. In addition, with the increasing of axial length, the corneal expansion was relatively limited. We investigated the biometric characteristics and the relation among the parameters of cataract surgery candidates which will be significant in this field of research.

\section{ACKNOWLEDGEMENT}

Thanks for the support of the Health Bureau Fund of Shang-hai, China (No. 2013379)

\section{AUTHOR'S NOTE}

Fei Yuan is the guarantor of integrity of the entire study; Chen-Li Feng, Yuan-Zhi Yuan and Fei Yuan proposed study concepts; Chen-Li Feng and Fei Yuan proposed study design; Yuan-Zhi Yuan and Xiao-Ping Ma gave 
definition of intellectual content; Chen-Li Feng, XiaoPing Ma and Yuan-Zhi Yuan did literature research; Chen-Li Feng did clinical studies, data analysis and manuscript preparation; Chen-Li Feng and Chen-Hao Zhang did data acquisition; Chen-Li Feng and Yuan-Zhi Yuan did statistical analysis; Fei Yuan, Xiao-Ping Ma and Yuan-Zhi Yuan edited manuscript and; Fei Yuan reviewed manuscript.

\section{Conflict of interest}

Authors declare that there is no conflict of interest.

\section{REFERENCES}

1. Ojaimi E, Morgan IG, Robaei D, Rose KA, Smith W, Rochtchina E et al. Effect of stature and other anthropometric parameters on eye size and refraction in a population-based study of Australian children. Invest Ophthalmol Vis Sci 2005; 46: 4424-9.

2. Saw SM, Carkeet A, Chia KS, Stone RA, Tan DT. Component dependent risk factors for ocular parameters in Singapore Chinese children. Ophthalmology 2002; 109: 2065-71.

3. Jorge J, Almeida J, Parafita M. Refractive, biometric and topographic changes among Portuguese university science students: a 3-year longitudinal study. Ophthalmic Physiol Opt 2007; 27: 287-94.

4. Onal S, Toker E, Akingol Z, Arslan G, Ertan S, Turan C et al. Refractive errors of medical students in Turkey: one year followup of refraction and biometry. Optom Vis Sci 2007; 84:175-80.

5. Konradsen TR, Zetterstrom C. A descriptive study of ocular characteristics in Marfan syndrome. Acta ophthalmol 2013; 91: 751-5.

6. Ferrer-Blasco T, Montes-Mico R, Peixoto-de-Matos SC, Gonzalez-Meijome JM, Cervino A. Prevalence of corneal astigmatism before cataract surgery. J Cataract Refract Surg 2009; 35: $70-5$.

7. Guan Z, Yuan F, Yuan YZ, Niu WR. Analysis of corneal astigmatism in cataract surgery candidates at a teaching hospital in Shanghai, China. J Cataract Refract Surg 2012; 38: 1970-7.

8. Khan MI, Muhtaseb M. Prevalence of corneal astigmatism in patients having routine cataract surgery at a teaching hospital in the United Kingdom. J Cataract Refract Surg 2011; 37: 1751-5.
9. Miyake T, Kamiya K, Amano R, Shimizu K. Corneal astigmatism before cataract surgery. Nippon Ganka Gakkai zasshi 2011; 115: 447-53.

10. Capozzi P, Morini C, Piga S, Cuttini M, Vadala P. Corneal curvature and axial length values in children with congenital/ infantile cataract in the first 42 months of life. Invest Ophthalmol Vis Sci 2008; 49: 4774-8.

11. Trivedi RH, Wilson ME. Keratometry in pediatric eyes with cataract. Arch Ophthalmol 2008; 126: 38-42.

12. Elabjer BK, Petrinovic-Doresic J, Duric M, Busic M, Elabjer E. Cross-sectional study of ocular optical components interactions in emmetropes. Coll Antropol 2007; 31: 743-9.

13. Hoffmann PC, Hutz WW. Analysis of biometry and prevalence data for corneal astigmatism in 23,239 eyes. J Cataract Refract Surg 2010; 36:1479-85.

14. Mallen EA, Gammoh Y, Al-Bdour M, Sayegh FN. Refractive error and ocular biometry in Jordanian adults. Ophthalmic Physiol Opt 2005; 25: 302-9.

15. Nemeth G, Szalai E, Berta A, Modis LJ, Modis Jr L. Astigmatism prevalence and biometric analysis in normal population. Eur $\mathrm{J}$ Ophthalmol 2013; 23:779-83.

16. Pan CW, Wong TY, Chang L, Lin XY, Lavanya R, Zheng YF et al. Ocular biometry in an urban Indian population: the Singapore Indian Eye Study (SINDI). Invest Ophthalmol Vis Sci 2011; 52: 6636-42.

17. Wickremasinghe S, Foster PJ, Uranchimeg D, Lee PS, Devereux $\mathrm{JG}$, Alsbirk PH et al. Ocular biometry and refraction in Mongolian adults. Invest Ophthalmol Vis Sci 2004; 45: 776-83.

18. Chen W, Zuo C, Chen C, Su J, Luo L, Congdon N. Prevalence of corneal astigmatism before cataract surgery in Chinese patients. J Cataract Refract Surg 2013; 39: 188-92.

19. Xu L, Zheng DY. Investigation of corneal astigmatism in phacoemisification surgery candidates with cataract. Chin J Ophthalmol 2010; 46: 1090-4.(in chinese)

20. Grosvenor T. Etiology of astigmatism. Am J Optom Physiol Opt 1978; 55: 214-8.

21. Park SH, Park KH, Kim JM, Choi CY. Relation between axial length and ocular parameters. Ophthalmologica 2010; 224:18893. 